\title{
Phenotypic and functional consequences of haploinsufficiency of genes from exocyst and retinoic acid pathway due to a recurrent microdeletion of $2 \mathrm{p} 13.2$
}

Jiadi Wen ${ }^{1 \dagger}$, Fátima Lopes ${ }^{2,3+}$, Gabriela Soares ${ }^{4}$, Sandra A Farrell ${ }^{5}$, Cara Nelson ${ }^{6}$, Ying Qiao ${ }^{1}$, Sally Martell ${ }^{1}$, Chansonette Badukke ${ }^{1}$, Carlos Bessa ${ }^{2,3}$, Bauke Ylstra ${ }^{7}$, Suzanne Lewis ${ }^{8}$, Nina Isoherranen ${ }^{6}$, Patricia Maciel2,3* and Evica Rajcan-Separovic ${ }^{1 *}$

\begin{abstract}
Background: Rare, recurrent genomic imbalances facilitate the association of genotype with abnormalities at the "whole body" level. However, at the cellular level, the functional consequences of recurrent genomic abnormalities and how they can be linked to the phenotype are much less investigated.

Method and results: We report an example of a functional analysis of two genes from a new, overlapping microdeletion of 2p13.2 region (from 72,140,702-72,924,626). The subjects shared intellectual disability (ID), language delay, hyperactivity, facial asymmetry, ear malformations, and vertebral and/or craniofacial abnormalities. The overlapping region included two genes, EXOC6B and CYP26B1, which are involved in exocytosis/Notch signaling and retinoic acid (RA) metabolism, respectively, and are of critical importance for early morphogenesis, symmetry as well as craniofacial, skeleton and brain development. The abnormal function of EXOC6B was documented in patient lymphoblasts by its reduced expression and with perturbed expression of Notch signaling pathway genes HES1 and RBPJ, previously noted to be the consequence of EXOC6B dysfunction in animal and cell line models. Similarly, the function of CYP26B1 was affected by the deletion since the retinoic acid induced expression of this gene in patient lymphoblasts was significantly lower compared to controls ( $8 \%$ of controls).

Conclusion: Haploinsufficiency of CYP26B1 and EXOC6B genes involved in retinoic acid and exocyst/Notch signaling pathways, respectively, has not been reported previously in humans. The developmental anomalies and phenotypic features of our subjects are in keeping with the dysfunction of these genes, considering their known role. Documenting their dysfunction at the cellular level in patient cells enhanced our understanding of biological processes which contribute to the clinical phenotype.
\end{abstract}

Keywords: 2p13 deletion, EXOC6B, CYP26B1, Developmental delay, Cranial/skeletal anomalies

\footnotetext{
*Correspondence: pmaciel@ecsaude.uminho.pt; eseparovic@cw.bc.ca

${ }^{\dagger}$ Equal contributors

${ }^{2}$ Life and Health Sciences Research Institute (ICVS), School of Health Sciences,

University of Minho, Braga, Portugal

${ }^{1}$ Child and Family Research Institute, Department of Pathology, University of

British Columbia, Vancouver, BC, Canada

Full list of author information is available at the end of the article
} 


\section{Background}

Chromosomal abnormalities involving the 2p13 chromosomal region were detected previously in subjects with developmental delay using traditional chromosome testing $[1,2]$. Abnormal features present in at least $50 \%$ of cases included abnormal head size/shape, nose, ears, chest and vertebral, digital and genital anomalies. The involvement of the CYP26B1 gene was suggested in a subject with a de novo inversion involving $2 \mathrm{p} 13$ and 2q34, who had a Klippel-Fiel anomaly (vertebral fusion of cervical spine), psychomotor retardation, speech limitation, facial asymmetry, ear abnormalities, and scoliosis $[3,4]$. Disruption of EXOC6B and its fusion with TNS3 from $7 \mathrm{p} 12$ due to a translocation $\mathrm{t}(2 ; 7)(\mathrm{p} 13 ; \mathrm{p} 12)$, was considered to be a possible cause of the intellectual disability, ADHD and congenital abnormalities (renal malformation, microcephaly, long bone diaphyseal broadening) in a subject reported by Borsani et al. [5].

CYP26B1 (cytochrome P450, family 26, subfamily B, polypeptide 1 ) is one of the three CYP26 gene isoforms (CYP26B1, CYP26A1 and CYP26C1) which encode the cytochrome-P450 enzymes that catabolize retinoic acid (RA) [6]. RA is the principal active metabolite of vitamin A and is an essential component of cell-cell signaling during vertebrate organogenesis [7]. Too little or too much RA causes the human malformation syndrome associated with vitamin A deficiency (VAD) or RA embryopathy, which includes craniofacial (e.g. ears, eyes, facial asymmetry), central nervous, musculoskeletal, and urogenital abnormalities [8-12]. Homozygous knockout of CYP26B1 in animals has been associated with postnatal mortality, abnormal craniofacial, limb and gonadal development $[13,14]$, while a conditional deletion (controlled expression) of CYP26B1 resulted in a less severe phenotype. The difference in the phenotypes was attributed to differing levels of activated retinoid signaling [15]. Although deletions of the whole CYP26B1 gene have not yet been reported in humans, homozygous point mutations of CYP26B1 were reported in two families, resulting in prenatal and early postnatal lethality, skeletal and craniofacial abnormalities, fusion of long bones, calvarial bone hypoplasia and sutural defects, resulting in craniostenosis and brachycephaly [16]. CYP26B1 mutations in both families led to a significantly attenuated ability to metabolize exogenously applied retinoic acid, confirming the impact of dysfunction of this gene on RA metabolism. Previous studies have shown that CYP26B1 is responsible for ATRA (all-trans retinoic acid) clearance in several tissues [17]. For example in T-cells, CYP26B1 is the only CYP26 enzyme up-regulated by ATRA and its expression regulates retinoic acid dependent signals in T-cells [18]. In addition, in many human cell lines CYP26B1 mRNA is inducible by retinoic acid treatment while in rodents cyp26b1 expression correlates with dietary vitamin A intake [19-22].

EXOC6B (exocyst complex component 6B) encodes a protein homologous to Sec15 in Saccharomyces cervisiae. It belongs to a multiprotein complex (exocyst) required for targeted secretion (exocytosis) which is crucial for cell polarity, growth and communication [23]. In Drosophila, sec15 promotes Notch signaling, through specific vesicle trafficking of delta ligand, and has a role in asymmetric division of sensory precursors and neuronal fate determination [24]. Drosophila neurons with sec15 mutations show loss of synaptic specificity and mislocalization of proteins known to affect synaptic specificity in photoreceptors [25]. Recently, Guichard et al. showed reduced transcription of Notch signaling effectors HES1 and RBPJ in knockdown Drosophila sec15 and in a human brain microendothelial cell line with abnormal EXOC6B function [26]. Notch signaling plays a pivotal role in the regulation of many fundamental cellular processes, such as acquisition of specific fates in context-dependent manner, differentiation and lineage decisions during embryonic development, neurogenesis, as well as morphogenesis involving regulation of left-right asymmetry $[27,28]$. Perturbations of the Notch pathway have been reported in human developmental disorders which demonstrate a variety of symptoms, including ID and/ or skeletal abnormalities (e.g. Allagile syndrome and spondylocostal dysostosis [29,30]).

We report the first description of the clinical and functional consequences of hemizygous deletion of the two genes, CYP26B1 and EXOC6B, located in chromosome region $2 \mathrm{p} 13$, and which are respectively, involved in retinoic acid and Notch signaling pathways of critical importance to normal human fetal development.

\section{Materials and methods \\ Whole genome array $\mathrm{CGH}$ analysis}

Genomic DNA was extracted from peripheral blood using the PUREGENE DNA Isolation Kits (Gentra, Minneapolis, $\mathrm{MN}$ ) for Subject 1 and Citogene ${ }^{\bullet}$ DNA isolation kit (Citomed, Portugal) for Subject 2. For Subject 1, Agilent $105 \mathrm{~K}$ array (version 4.0, June 2006, Agilent Technologies, CA, USA) analysis was performed as previously described. ${ }^{25} \mathrm{CNV}$ selection was done by Agilent DNA Analytics (version 3.5.14, Agilent Technologies) using the ADM-2 algorithm (cutoff 6.0), followed by a filter to select regions with three or more adjacent probes and a minimum average $\log 2$ ratio +0.25 [31]. The deletion of Subject 1 was de novo, as determined by FISH using probe RP11-91 F23.

For Subject 2, the aCGH analysis was performed using a CGH Agilent $180 \mathrm{~K}$ custom array design accessible through the gene expression omnibus (GEO) accession number GPL15397. Previously published protocol was 
used [32]. Image analysis was performed using the across-array methodology described previously [33]. CGH data was analyzed using Nexus Copy Number 5.0 software with FASST Segmentation algorithm. The deletion was determined to be de novo using the same array for both parents.

For both cases, the array design, database consultation and comparative analysis was performed using genome build 36.1/HG18.

\section{Functional studies}

Immortalized EBV transformed lymphoblastoid cell lines (LCL) from Subject 1 were cultured in RPMI media containing 10\% FBS, 50 units $/ \mathrm{mL}$ penicillin, $50 \mu \mathrm{g} / \mathrm{mL}$ streptomycin. Cells were maintained in a humidified $37^{\circ} \mathrm{C}$ incubator with $5 \% \mathrm{CO}_{2}$. Control cells were obtained from healthy subjects, the majority of which aged $28-50$ years.

\section{RNA expression}

Total RNA was extracted using an RNeasy Plus Mini kit (Qiagen) from Subject 1-derived LCLs and whole blood collected in Tempus tubes. Aliquots $(\sim 500 \mathrm{ng})$ of the total RNA extracts prepared from were subsequently reverse-transcribed into cDNA using GeneAmp Gold RNA PCR Core Kit (Applied Biosystems).

The expression of EXOC6B and CYP26B1 was first assessed in RNA extracted from control whole blood and control LCLs by real-time qPCR using the ABI PRISM 7300 Sequence Detection System (Perkin-Elmer Applied Biosystems). The specific nucleotide sequences for primers of $E X O C 6 B$ and $C Y P 26 B 1$ were as follows: EXOC6B Forward 5'-GAC CTC ATT GCC TTT CTT CGT A-3', Reverse 5'-CAA GCT GAC ATA CAC GCT GT-3'(mapped to exons 18-19); CYP26B1 primer set 1; Forward 5'-ACA CAG GGC AAG GAC TAC T-3', Reverse: 5'-GCA TAG GCC GCA AAG ATC A-3'(mapped to exon 4-5); CYP26B1 primer set 2: Forward: 5'CTA CCT GGA CTG CGT CAT CA-3', Reverse: 5'-CCC GGA TGC TAT ACA TGA CA-3' (mapped to exon 5-6). $E X O C 6 B$ had a detectable transcript, while no transcript was detected with CYP26B1 primers for exons 4-5 and exons 5-6 in control whole blood, nor transformed lymphoblasts.

Real-time qPCR was performed for $E X O C 6 B$ and its downstream genes HES1 and RBPJ using SYBR ${ }^{\oplus}$ Green PCR Master Mix (Applied Biological Materials Inc). Primer sequences were as follows: HES1 Forward: 5'-GAG CAC AGA AAG TCA TCA AAG C-3' (mapped to exons 1-3), Reverse: 5'-TTC CAG AAT GTC CGC CTT C-3'; RBPJ Forward: 5'-GGG ATA GGA AAT AGT GAC CAA GA-3', reverse: 5'-GTG CTT TCG CTT GTC TGA GT-3' (mapped to exons 7-8).

Quantification of expression level of EXOC6B, HES1 and $R B P J$ was performed in comparison to actin. All
PCR reactions were performed in triplicate, with the mean of $2^{-\Delta \Delta C t}$ values [34] being used to determine mRNA levels for Subject 1 in comparison to the mean expression level for three controls. Significance was calculated using the Student's t test (VassarState Statistical Computation website). Values were considered statistically significant with a p-value of $<0.05$.

\section{Protein expression}

LCLs were washed three times in PBS and incubated in $1 \mathrm{~mL}$ RIPA buffer (Thermo Scientific, USA), supplemented with Halt Phosphatase Inhibitor Cocktail (Thermo Scientific, USA) for 15 minutes on ice. Cell lysates were centrifuged at $10,000 \times \mathrm{g}$ for 15 minutes at $4^{\circ} \mathrm{C}$, and the supernatants were used for Western blotting. Cell lysate protein concentrations were determined using a $\mathrm{DC}^{\mathrm{rm}}$ Protein Assay (BioRad laboratories, USA). Western blots containing cell-lysate aliquots $(\sim 30 \mu \mathrm{g})$ were prepared and immunoblotted using a polyclonal antibody directed against human RBPJ or a monoclonal antibody against human HES1 (Abcam, Cambrige, MA, USA). Three antibodies against human EXOC6B were tested in this study (Sec15B(C-14) (goat polycolonal antibody):sc34375, Santa Cruz Biotechnology,Inc. Anti-EXOC6B antibody (rabbit polycolonal antibody): ab116383, Abcam Inc. Anti-EXOC6B antibody (mouse polycolonal antibody): H00023233-B01P, Novus Biologicals) but did not provide a clear or visible band at the expected size, amenable to interpretation. To standardize the amounts of protein loaded into each lane, the blots were reprobed with a monoclonal antibody directed against human $\beta$-actin (NovusBiologicals, Littleton, USA). The ECL Western Blotting system was used to detect the amount of each antibody bound to antigen and the resultant photographic films were analyzed by UV densitometry (GE Healthcare Life Sciences, Pittsburgh, USA). The absorbance values obtained for HES1 and RBPJ were then normalized relative to the corresponding $\beta$-actin absorbance value. The average of HES1 or RBPJ protein expression was obtained from three independent replicates from the Subject and the control samples. P values for two tailed Student test were considered statistically significant if $<0.05$.

\section{CYP26B1 expression upon ATRA induction}

Cells from seven control subjects (aged 2-42 years) and Subject 1 were plated in 6-well plates at a density of 400,000 cells $/ \mathrm{mL}$ in $3 \mathrm{~mL}$ and treated in triplicate with $1 \mu \mathrm{M}$ all-trans retinoic acid (ATRA) or an equal volume of vehicle (ethanol) in triplicate and incubated in the dark for 72 hours. Following treatment, cells were pelleted and resuspended in $1 \mathrm{~mL}$ Tri-Reagent Solution (Life Technologies, Grand Island, NY) followed by repeated pipetting to lyse the cells. RNA was then isolated according to manufacturers instructions and RNA 
quantity and quality were determined using a NanoDrop 2000c spectrophotometer (Thermo Scientific, Waltham, MA) by measuring the absorbance at $260 \mathrm{~nm}$ and $280 \mathrm{~nm}$. Complimentary DNA (cDNA) was generated from $1 \mu \mathrm{g}$ total RNA by reverse transcription using the TaqMan reverse transcription reagents kit (Life Technologies, Grand Island, NY), as previously described [17,35]. TaqMan Gene Expression Master Mix, PCR primers, and fluorescent probes were obtained from Applied Biosystems (Life Technologies, Grand Island, NY). Probes were labelled with the 5' reporter dye FAM (CYP26A1 and CYP26B1) or VIC (GAPDH). Primer probe pairs used were: CYP26A1 (Hs00219866_m1), CYP26B1 (Hs00175627_m1), and the endogenous control GAPDH (RefSeq: NM_002046.3). Quantitative realtime PCR was conducted on a StepOnePlus Real-Time PCR instrument (Applied Biosystems, Foster City, CA) as previously described $[17,35]$. The fold-increase in CYP26A1 and CYP26B1 mRNA was calculated using the $\Delta \Delta C_{t}$ method (fold difference $=2^{-\Delta \Delta C t}$ ) by comparing the ATRA-treated cells to the vehicle treated controls. Differences between controls and patient were tested by t-test using GraphPad Prism 5.0. Values were considered statistically significant with a p-value $<0.05$. Grubb's test was used to determine if any of the subjects met the criteria of an outlier.

The use of tissues was approved by the Committee for Ethical Review of Research involving Human Subjects, University of British Columbia. Written informed consent was obtained from the patients' parents for the publication of this report and any accompanying images.

\section{Results}

\section{Clinical description}

\section{Subject 1}

This male was seen by a geneticist as a neonate because of dysmorphic features, including an asymmetric crying face with a right facial nerve paralysis, a dysplastic right ear, brachycephaly (Figures 1 and 2) and mild contractures of the knees and elbows (which disappeared by five months). The pregnancy was complicated by maternal nausea and vomiting, with only a five pound maternal weight gain. Birth weight was on the 10th centile. A $2 \mathrm{~mm}$ secundum atrial septal defect closed in early infancy. His parents are not consanguineous. A paternal great-uncle has intellectual disability while another paternal great-uncle's adult son has

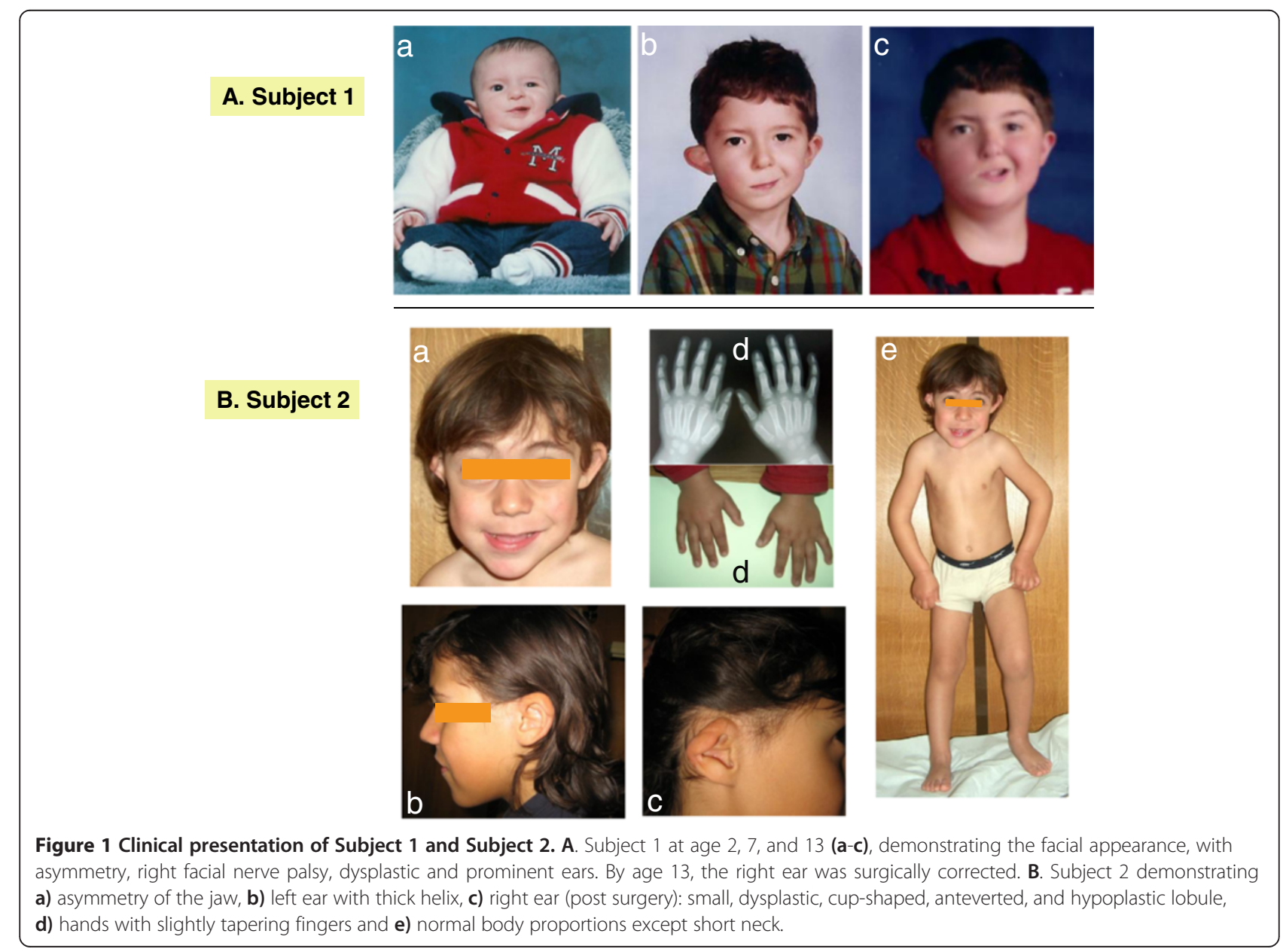




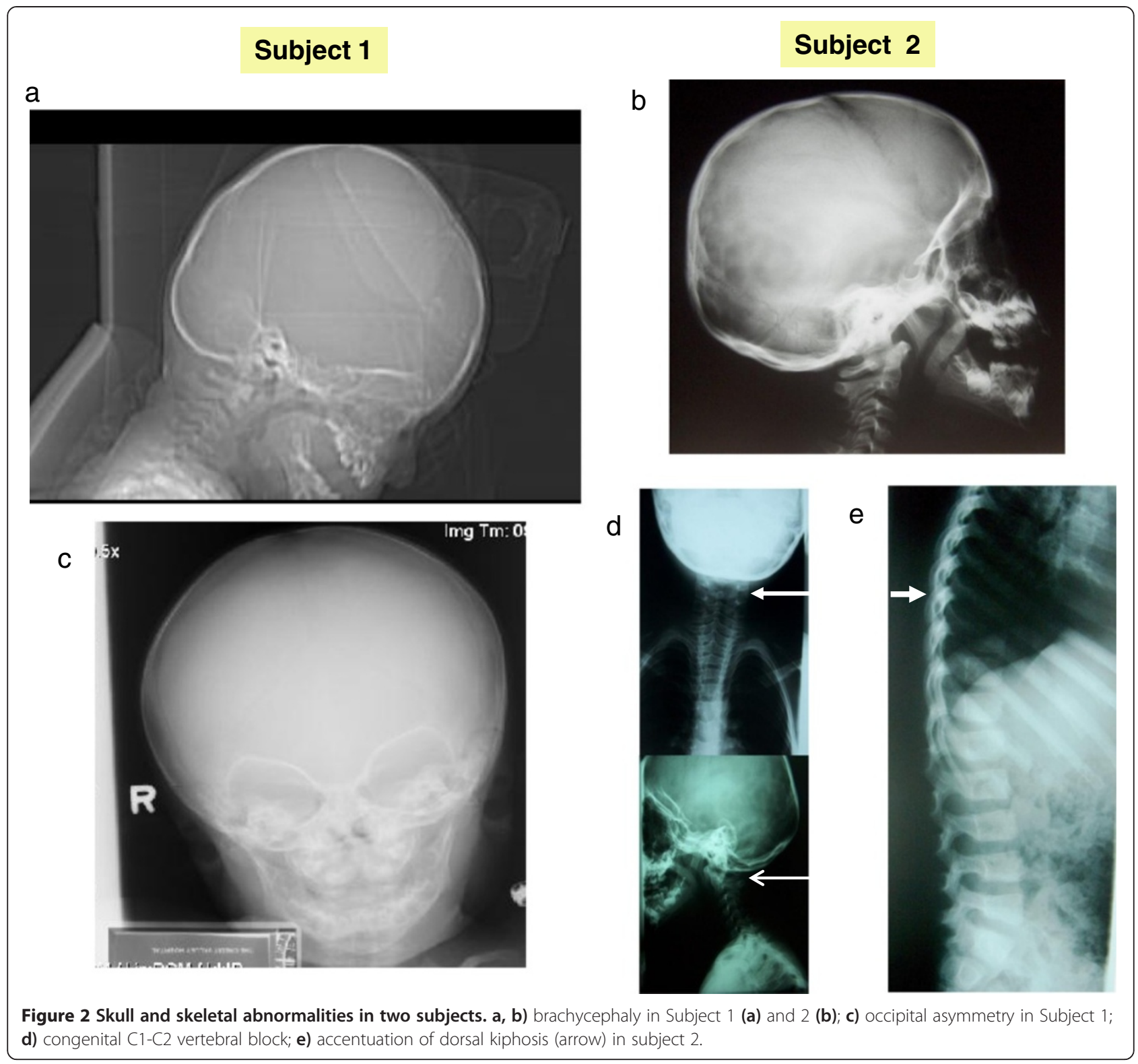

"autistic like features" at age 40. The remainder of the family history is unremarkable.

As an infant, he had difficulty transitioning to solid foods, with gagging and vomiting. He walked at 13 months. At 22 months, he had only a few words. By three years, he was not using any words regularly although he would use a word for a few days and then stop. With most activities, he was not able to stay on track, being quite hyperactive and distractible. His clinical diagnosis of autism was confirmed by an assessment using ADOS at age $2 \frac{1 / 2}{2}$ years. At 13 years of age, his academic functioning was somewhat variable, with mathematics being comparable to the skill level of a ten year old, while the level for other subjects was comparable to an eight year old.
At 22 months, height was above the 50th centile, weight was below the 10th centile, and OFC was on the 3rd centile. He had brachycephaly, which had been seen in infancy. The metopic suture, which was open at 7 months, was closed at 22 months. The left ear was low set, while the right was dysplastic, prominent, with a thin helix and an abnormal crural fold. His face appeared to be asymmetric, due to the right facial nerve palsy. Eye examination was normal except for right eyelid paralysis, secondary to the right facial nerve palsy. The remainder of the physical examination was unremarkable.

Chromosome testing was normal, including FISH at 22q11.2. A CT scan of the brain was normal. Skull radiographs at age 7 months showed a shortened anteriorposterior diameter relative to width. There was slight 
asymmetry of the appearance of the orbits, with the left side a little larger and slightly more prominent superiorlaterally (Figure 2). No obvious sutural stenosis was evident. At age 14 , a C-spine radiograph was normal.

\section{Subject 2}

The Subject is a 9 year old boy referred for a genetics consultation because of delayed milestones and dysmorphic faces. His parents are non-consanguineous and he has one healthy sister. His maternal uncle died at the age of 3 months, of unexplained sudden death. No other family history of developmental problems or congenital anomalies was reported. At the age of 3 years, he had two episodes that raised the suspicion of absence seizures, but the EEG was normal. Delayed development was noted, especially in language. He spoke few words with no sentences. Mild motor delay also was described, with unaided walking starting at 16 months.

At four years, his growth parameters were normal (weight: 75 th percentile; height: $50-75$ th percentile and OFC: $50-75$ th percentile). At five years he had a global developmental quotient of 53.4 on the Griffiths Mental Developmental Scale evaluation. His I.Q. at the age of 7 years based on the Wechsler Intelligence Scale was 73 (borderline mental retardation), with a verbal scale of 66 and performance scale of 89 . The proband was dysmorphic with a triangular face, brachycephaly, hypertelorism, upslanting palpebral fissures, thin lips, hypertrophic gums, a pointed chin and short neck (Figure 1). He had abnormal ears (asymmetric, dysplastic and low-set). The right ear was small, cup-shaped, anteverted and the lobule was hypoplastic. The left ear was bigger than the right, with a thick helix. Asymmetry of the jaw was noted, with the left side longer than the right side. His fingers were slightly tapering. Radiographs revealed congenital $\mathrm{C} 1-\mathrm{C} 2$ vertebral fusion, with accentuation of dorsal kyphosis (Figure 2).

Subject 2 displayed stereotypies, aggressive behavior, hyperactivity (including jumping if agitated) and attention deficit. Brain MRI, echocardiogram, abdominal ultrasound, ophthalmology and ENT examinations were normal. Radiographs of upper and lower limbs, pelvis and rib cage did not reveal abnormalities. Chromosome, FISH for the 22q 11.2 region, molecular testing for Fragile $\mathrm{X}$ and metabolic studies (plasma aminoacids, urine organic acids, CDT, creatine and guanidinoacetic acid in urine, 7-dehidrocholesterol, lactate, pyruvate and ammonia) were normal.

The clinical description of the two subjects is summarized in Additional file 1: Table S1.

\section{Array CGH}

For Subject 1, aCGH revealed a $0.78 \mathrm{Mb}$ de novo deletion at chromosome region 2p13.2-13.3 (72,140,702$72,924,626)$, containing 2 genes. Subject 2 had a $4 \mathrm{Mb}$ de novo deletion detected at chromosome region 2p13.1p13.3 (chr2:70,748,414-74,840,026), containing 62 genes (Figure $3 \mathrm{~A}$ and $3 \mathrm{~B}$ ). The region of overlap between both cases is $0.78 \mathrm{Mb}$, located between the 72,140,702$72,924,626$ genomic positions and encompasses the CYP26B1 and EXOC6B genes.

\section{Functional studies of EXOC6B and notch effector genes HES1 and RBPJ in subject 1}

Significant reduction of RNA expression for all three genes (EXOC6B, RBPJ and HES1) was detected in lymphoblasts from Subject 1 in comparison to three controls (Figure 4A). Protein expression for both HES1 and RBPJ was also significantly reduced in his lymphoblasts (Figure 4B and 4C), however, EXOC6B protein level could not be assessed due to a number of non-specific bands or a single band of an unexpected size in controls obtained with three commercial EXOC6 antibodies.

We noted that in control lymphoblasts, the baseline level of HES1 and RBPJ expression was significantly higher than EXOC6, possibly due to the fact that EBV viral protein EBNA2 induces RBPJ expression [36] (Figure 4A). To eliminate the effect of EBV transformation on RBPJ and HES expression, whole blood was used from Subject 1 and the controls. Similarly to the lymphoblasts, RNA expression of EXOC6 and RBPJ was significantly reduced in the Subject's whole blood in comparison to a control. However, HES1 expression was significantly higher in whole blood of Subject 1 than in the control bloods (Figure 5). Protein from whole blood was not available for assessment of RBPJ and HES1 expression levels.

\section{ATRA induction of CYP26B1 expression}

EBV transformed lymphoblasts from seven controls and Subject 1 were treated with $1 \mu \mathrm{M}$ ATRA for 3 days. To obtain a quantitative comparison of the ATRA induction of CYP26B1 in Subject 1 LCLs versus LCLs from controls, the fold difference in CYP26B1 mRNA induction with ATRA treatment was calculated for Subject 1 and controls in comparison to the vehicle treated cells. ATRA induction of CYP26B1 mRNA in LCLs from one control subject $(56.7 \pm 3.7$ fold) was determined to be an outlier by Grubb's test from the other controls and was excluded from further analysis. The CYP26B1 mRNA fold-induction from the six remaining control cells was averaged to show the range in induction in control LCLs (Figure 6A). CYP26B1 mRNA induction with ATRA treatment was significantly less in Subject 1 compared to averaged control cells $(1.9 \pm 1.5$ fold in subject and $12.9 \pm$ 7.3 fold in controls,) (Figure 6A).

The relatively minimal expression of CYP26B1 in ATRA-treated cells from Subject 1 raised the possibility of compensatory expression of CYP26A1 to regulate retinoic acid levels. ATRA-treatment resulted in minimal 


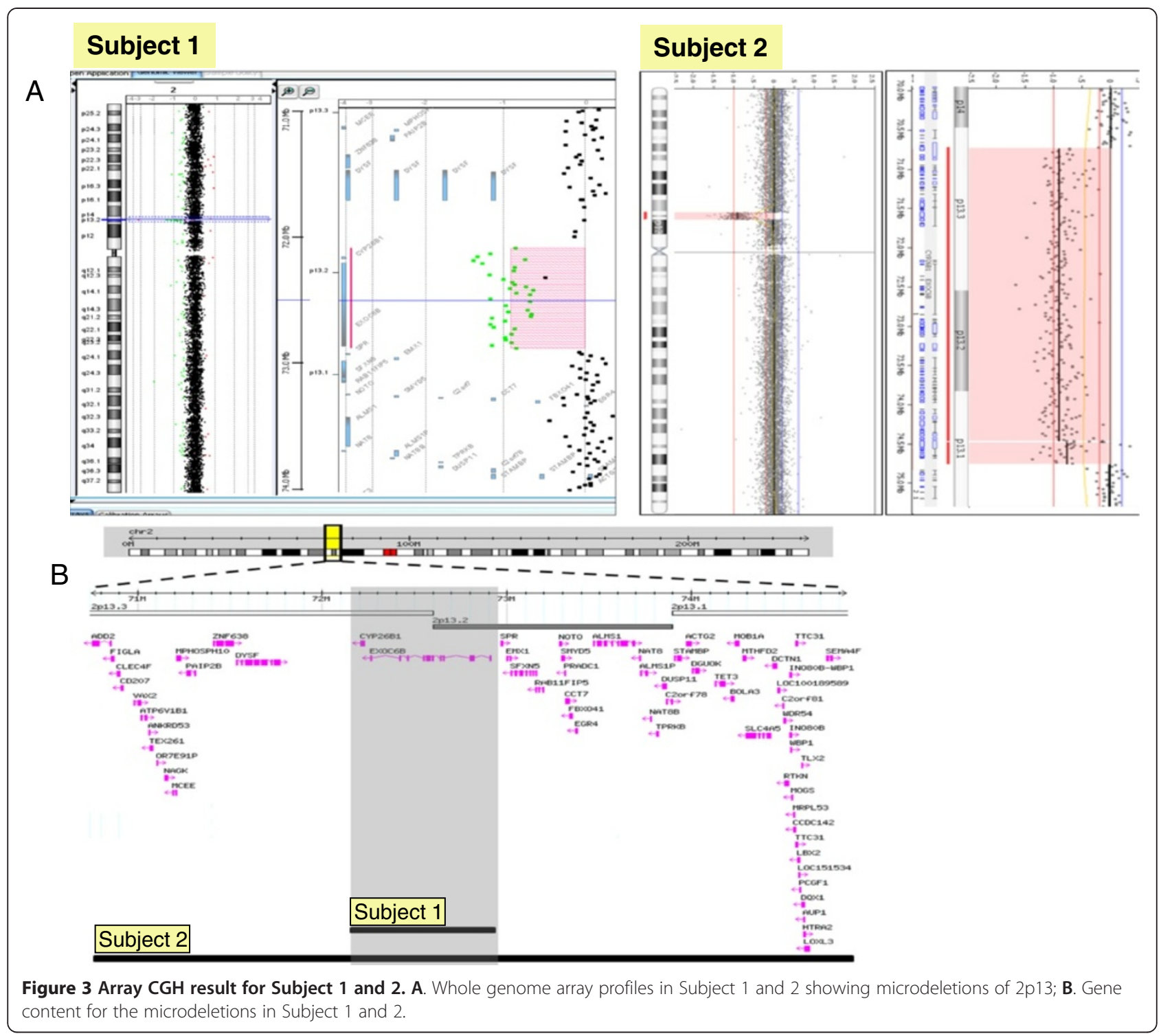

induction of CYP26A1 mRNA in all LCLs which is in agreement with the lack of CYP26A1 induction and overall low to undetectable expression in blood [18]. CYP26A1 induction was not significantly different in control LCLs $(3.4 \pm 3.4$ fold) compared to Subject 1 LCLs $(0.9 \pm 0.9$ fold $)$ as shown in Figure 6B. Thus, CYP26A1 was not induced to a greater extent in response to ATRA treatment in cells with a deletion of CYP26B1. To exclude the possibility that CYP26A1 expression was higher in Subject 1 cells compared to control cells prior to ATRA treatment, we compared the $\Delta$ Ct values of the vehicle-treated cells and found no differences $(\mathrm{P}>0.05)$. Hence, it does not appear that CYP26A1 mRNA expression is upregulated to compensate for reduced CYP26B1 expression in Subject 1 LCLs. While upregulation of Cyp26a1 has been observed in Cyp26b1 $1^{-/-}$ mice at specific developmental stages and tissues during mouse organogenesis, overall, the expression patterns and function of Cyp26a1 and Cyp26b1 are considered nonoverlapping during mouse development [37-39].

\section{Discussion}

We report a 2p13.1-p13.3 microdeletion observed in two subjects with clinical effects on the cognitive function (ID and language delay), behaviour (hyperactivity), and development of the craniofacies (facial asymmetry, unusually shaped and asymmetric ears and brachycephaly). Skull and vertebral bone abnormalities included slight asymmetry of the appearance of the orbits and delayed closure of the metopic suture in Subject 1 and congenital C1-C2 vertebral fusion, and accentuation of dorsal kyphosis in Subject 2. Previous cases with cytogenetic deletions/ 


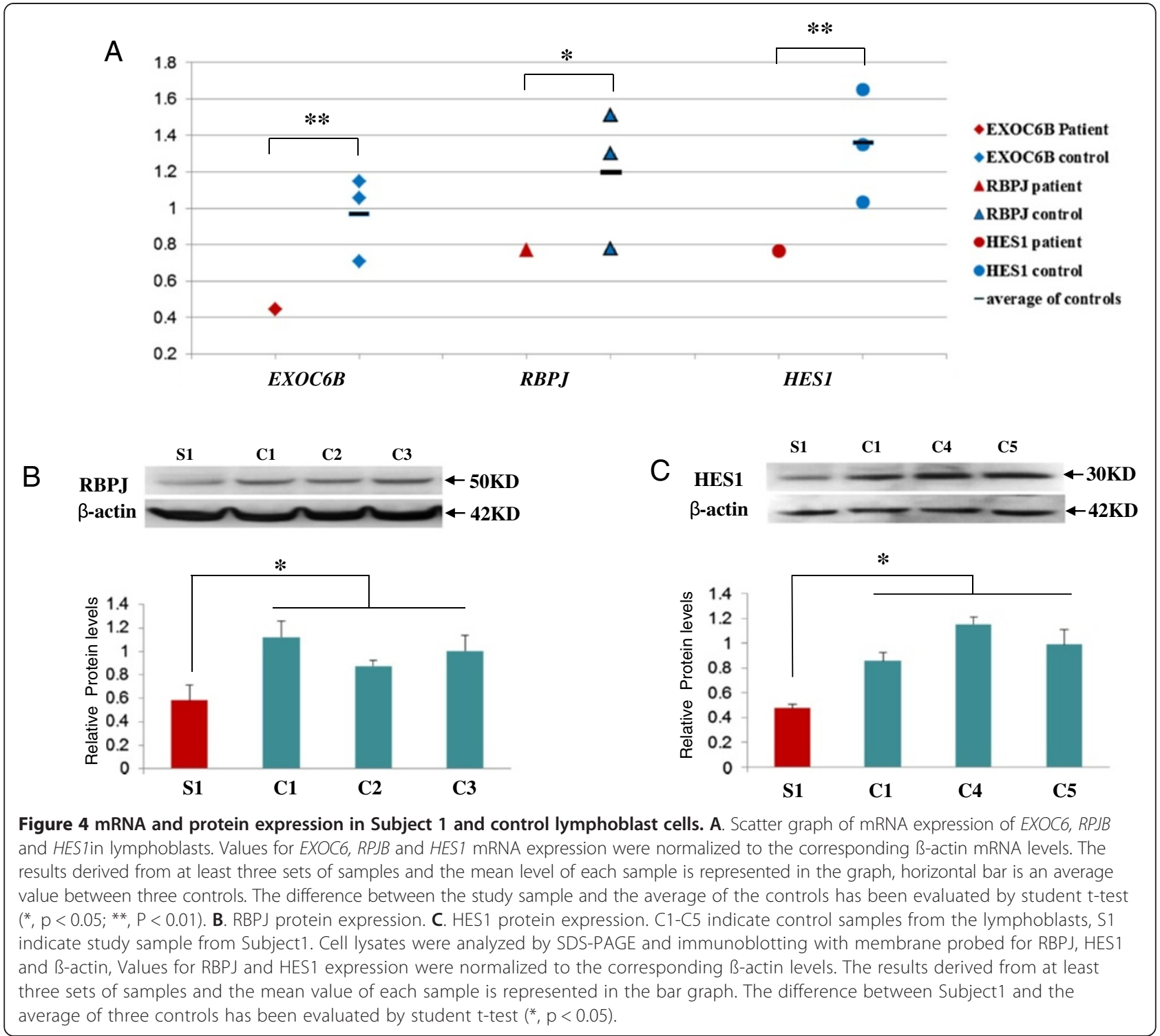

disruptions of this region all had developmental delay and the majority had head/facial anomalies, ear and skeletal abnormalities [1,2].

The overlapping deleted region of our two cases encompasses two genes, EXOC6B and CYP26B1, both of which showed altered function in whole blood and/or LCLs from Subject 1. The reduced expression of EXOC6B in LCLs and whole blood could be the cause of the observed perturbed Notch signaling (i.e. HES1 and RBPJ expression change), considering the similar effect of EXOC6B knockout on Notch signaling in Drosophila. ${ }^{20}$ The reduction of RNA expression of EXOC6B and RBPJ was concordant between LCLs and whole blood, and the expression of the $R B P J$ protein also was reduced in Subject 1 lymphoblasts. However, HES1 had reduced RNA and protein expression in LCLs and increased RNA expression in whole blood.
The discrepancy in the pattern of abnormal expression of HES1 in different cell types could be due to the difference in the Notch signaling pathway in lymphoblasts which contain dedifferentiated B cells vs. whole blood which contains multiple differentiated cell lineages. Cell-specific over or underexpression of Hes1 has been reported in different regions of the brain in $R b p j$ knockout mice [40].

EXOC6B germline mutations or deletions have yet not been reported in humans. A homozygous mutation in EXOC6B's paralogue EXOC6A has been reported in mice with hemoglobin-deficit (hbd) due to defective iron transport in the endocytosis cycle [41] while haploinsufficiency of EXOC6A due to a $0.3 \mathrm{Mb}$ microdeletion at $10 \mathrm{q} 23.33$, was reported in a family with nonsyndromic bi- and unilateral optic nerve aplasia [42]. Interestingly, this microdeletion also included two CYP genes, CYP26A1 


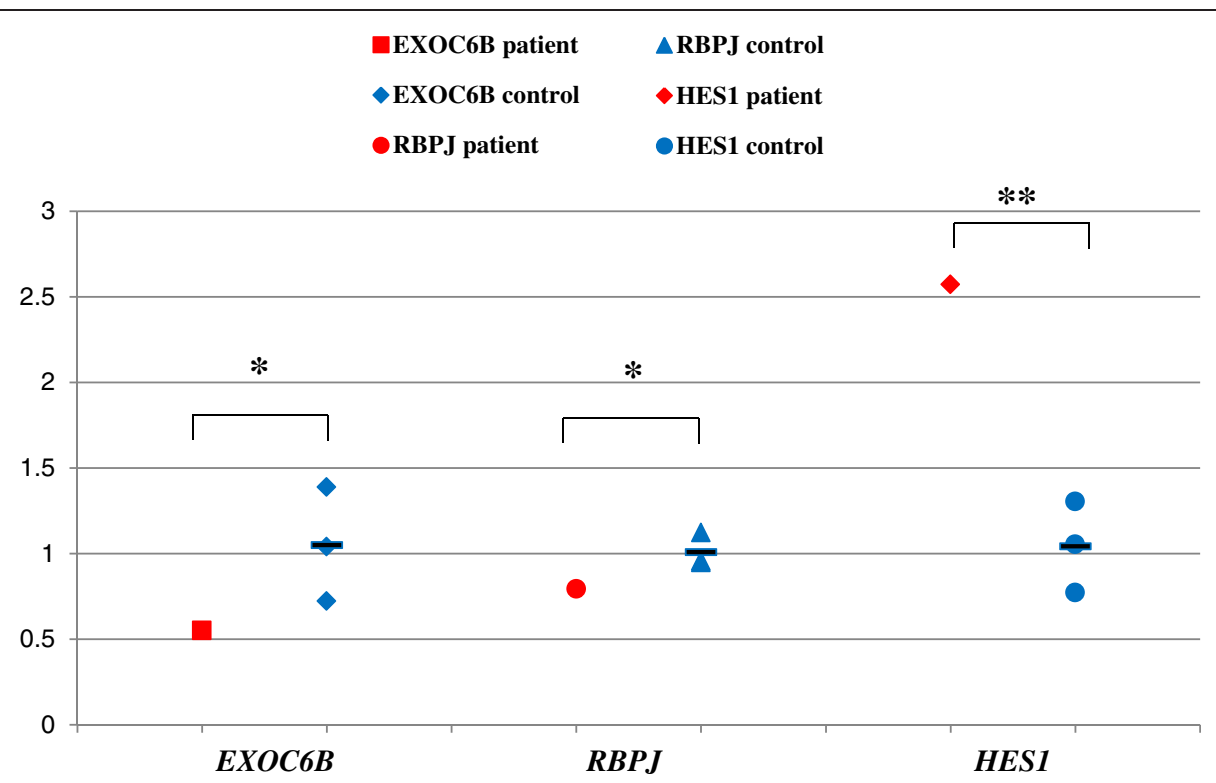

Figure 5 mRNA expression of EXOC6, RPJB and HES1 in whole blood of Subject 1 and controls. Values for EXOC6, RPJB and HES1 mRNA expression in whole blood were normalized to the corresponding B-actin mRNA levels. The results derived from at least three sets of samples and the mean level of each sample is represented in the scatter graph, horizontal bar is an average value between three controls. The difference between subject 1 and the average of the controls has been evaluated by student t-test $\left.{ }^{*}, \mathrm{p}<0.05 ;{ }^{* *}, \mathrm{P}<0.01\right)$.

and CYP26C1. In contrast to very little information on genetic defects of EXOC6B and their role in disease, genetic abnormalities of HES1 and RBPJ have been associated with a number of developmental defects in vertebrates. Homozygous Hes1 and Rbpj knockout mice showed severe developmental defects and lethality $[43,44]$, while Rbpj heterozygous knockout mice demonstrated learning deficits [29]. In humans, increased expression of HES1 was reported in Down syndrome [45] and recent exome sequencing studies revealed heterozygous mutations in $R B P J$ and reduced expression of HES1 in two families with Adams-Oliver syndrome, associated with congenital cutis aplasia, terminal limb abnormalities (asymmetric shortening of the hands and feet in one of the families) and a range of cognitive functioning (from intellectual disability to normal) [46].

The deletion of CYP26B1 gene in both our Subjects is also likely to contribute to their abnormal phenotype, based on abnormal RA metabolism in Subject 1, as evidenced by significantly attenuated induction of CYP26B1 expression with ATRA in comparison to controls. To the best of our knowledge, there are no reports on the effect of CYP26B1 gene haploinsufficiency in humans. Previously, in two other families, two different homozygous mutations of CYP26B1 have been reported, resulting in lethality, skeletal and craniofacial abnormalities, including fusion of long bones, calvarial bone hypopasia and craniosynostosis [16]. In one
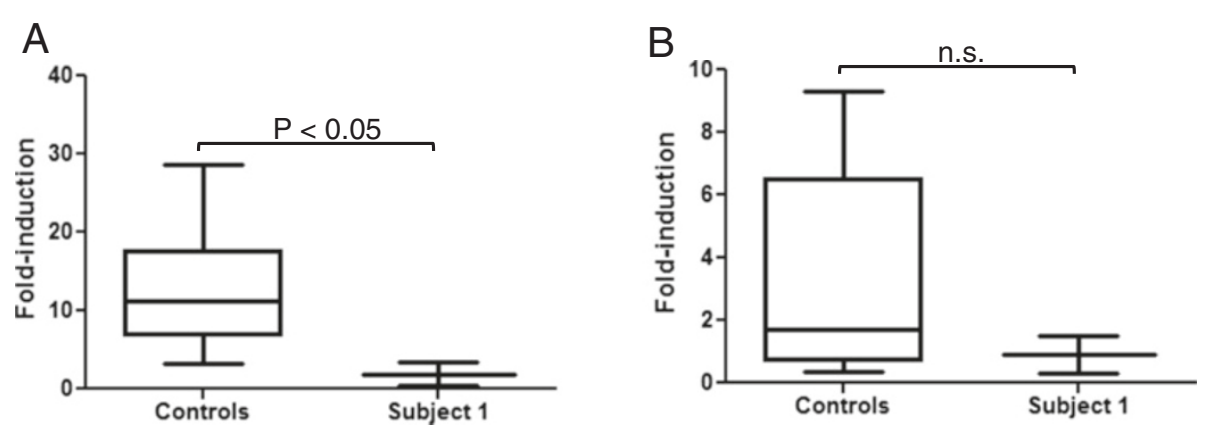

Figure 6 Induction of CYP26B1 and CYP26A1. A. Fold induction of CYP26B1 mRNA expression. CYP26B1 was induced significantly more (*P $<$ 0.05 ) in the control cells as compared to the Subject 1 (S1) cells with a chromosomal deletion of CYP26B1 after treatment with ATRA. B. Induction of CYP26A1 mRNA expression in ATRA-treated cells. There was no significant difference (n.s.; P > 0.05) in CYP26A1 induction between the control cells and Subject 1 cells. 
of the families with the hypomorphic mutation, brachycephaly and wide sagittal sutures were noted. The two mutationbearing constructs had attenuated ability to metabolize ATRA (36\% and 86\%) [16]. In our Subjects, the decreased RA catabolism and increased sensitivity to RA, as a consequence of CYP26B1 deletion could explain features similar to those noted by Laue et al. [16] (e.g. brachycephaly for both subjects, and for Subject 1, the delayed closure of the metopic suture) and in general compromise the craniofacial, skeletal development and neuronal functioning. With regard to the later phenotype, it is of interest that Subject 1 had an asymmetric crying face as a consequence of a right facial nerve palsy which previously was associated with RA exposure or early embryonic insult $[11,47]$. The phenotype of the subjects is in agreement with developmental effects of CYP26B1 deletion in experimental animals [37]. CYP26B1 null mice have craniofacial abnormalities, exhibit abnormal ear development and other bone and cartilage deformities [13]. Interestingly, the truncated limbs observed in $\mathrm{CYP}_{26 \mathrm{~B}}{ }^{-/-}$mice were absent in the patients. Similarly, in the zebrafish CYP26B1 deletion has been shown to result in overall defective craniofacial cartilage development with smaller head, severely decreased number of vagal branchiomotor neurons and defective or absent jaw cartilage [48].

It is intriguing to note the lethal phenotype in two subjects reported by Laue et al. [16] due to homozygous mutations of $C Y P 26 B 1$ in comparison to the survival and developmental abnormalities in our subjects with hemizygous CYP26B1 deletion. The presence of one normal copy of the gene in each of our subjects and the efficiencies of the other two remaining RA catabolizing CYP26 genes (CYP26A1 and CYP26C1), possible compensatory changes in other proteins known to regulate retinoic acid, such as RALDH $[8,49,50]$ and environmental influences, such as diet and pharmacological treatment, [6,51] all could have an effect on the phenotypes. Phenotypic variability also was noted for carriers of CYP26A1, CYP26C1 and EXOC6A deletions within one family [42], ranging from normal vision, to uni- and bilateral optic nerve hypoplasia and variable levels of cognitive functioning (normal to impaired).

The combined effect of deletion of both EXOC6B and CYP26B1 on Notch and RA signaling, and consequently the phenotype, also should be considered in our subjects. Interaction of RA and Notch signaling in determination of left/right asymmetry and segmentation has been reported by Echeverri and Oates [52] who noted the requirement of $R b p j$ function for expression of RA catabolizing enzyme Cyp26a1 which in turn, is needed for left/right symmetric cyclic gene expression. Vermot et al. [53] demonstrated that reduced levels of RA were associated with abnormal Hes1 expression and asymmetry in mouse embryos, while Castella et al. [54] showed that addition of RA raises the level of HES1 protein expression in in vitro cell culture.

Subject 2 had additional phenotypic features not noted in Subject 1, which might be explained by the larger size of the 2p13.1-13.3 deletion, interaction of its integral genes and genetic background. For example, seizure-like episodes were not noted in Subject 1, but were present in Subject 2 and a Decipher subject, \# 257412, with developmental delay, whose deletion of 2p12-13.3 was 6.8 $\mathrm{Mb}(70,889,254-77,746,500)$, and his features included coarse faces, a flat malar region, myopathic hypotonia and prominent ears. The cervical fusion and spine abnormality are unique for Subject 2 and are of interest, considering the report of a subject with Klippel-Fiel anomaly, who had a balanced inversion involving chromosome 2p13 and congenital fusion of the cervical spine, impairment of hearing, psychomotor retardation, speech limitation, short stature, spinal asymmetry and scoliosis [3]. The genes disrupted/deleted by this chromosome rearrangement are unknown, however, it was speculated that CYP26B1 was involved based on the similar vertebral phenotype observed in zebrafish with $C y p 26 b 1$ mutations [4].

Our report is unique as it provides a new insight into the phenotypic and functional consequences of hemizygous deletion of two genes implicated in Notch and Retinoic acid signaling. It also supports the previous cell line and animal model based observation of exocyst role in Notch signaling. Further studies of exocyst complex function in patient cells would be of interest for understanding of its role in human disease.

\section{Additional file}

Additional file 1: Table S1. Clinical features of Subject 1 and 2.

Competing interests

The authors have no competing interests to declare.

\section{Authors' contribution}

JW, ERS, CN, NI, FL and PM: Conception, design, analysis and interpretation of data. Drafting the article or revising it critically for important intellectual content. SAF, GS, SL, CB, YQ, BY and SM: Analysis and interpretation of data. Drafting the article or revising it critically for important intellectual content. All authors read and approved the final manuscript.

\section{Authors' information}

Patricia Maciel and Evica Rajcan-Separovic are co-corresponding authors.

\section{Acknowledgments}

We would like to sincerely acknowledge the families of the presented cases for participation in the genetic studies and for allowing this publication. This work was supported by funding from the Canadian Institutes for Health Research (CIHR) (RT-64217; PI: MESL and MOP 74502; PI: ERS), Autism Speaks (PI: MESL) and Fundação para a Ciência e Tecnologia (PIC/IC/83026/2007. MES and ERS are Career Investigators with the Michael Smith Foundation for Health Research. The experiments were supported in part by a US National institutes of Health grant R01 GM081569 (NI and CN). 
This study makes use of data generated by the DECIPHER Consortium. A full list of centres which contributed to the generation of the data is available from http://decipher.sanger.ac.uk and via email from decipher@sanger.ac.uk. Funding for the project was provided by the Wellcome Trust.

\section{Author details}

${ }^{1}$ Child and Family Research Institute, Department of Pathology, University of British Columbia, Vancouver, BC, Canada. ${ }^{2}$ Life and Health Sciences Research Institute (ICVS), School of Health Sciences, University of Minho, Braga, Portugal. ${ }^{3}$ ICVS/3B's - PT Government Associate Laboratory, Braga/Guimarães, Portugal. ${ }^{4}$ Center for Medical Genetics Dr. Jacinto Magalhães, National Health Institute Dr Ricardo Jorge, Porto, Portugal. ${ }^{5}$ Genetics, Trillium Health Partners, Credit Valley Hospital Site, Mississauga, ON, Canada. ${ }^{6}$ Department of Pharmaceutics, School of Pharmacy, University of Washington, Seattle, WA, USA. ${ }^{7}$ Department of Pathology, VU University Medical Center, Amsterdam, The Netherlands. ${ }^{8} \mathrm{Child}$ and family Research Institute, Department of Medical Genetics, University of British Columbia, Vancouver, BC, Canada.

Received: 21 February 2013 Accepted: 3 July 2013

Published: 10 July 2013

\section{References}

1. Lacbawan FL, White BJ, Anguiano A, Rigdon DT, Ball KD, Bromage GB, Yang X DiFazio MP, Levin SW: Rare interstitial deletion (2)(p11.2p13) in a child with pericentric inversion (2)(p11.2q13) of paternal origin. Am J Med Genet 1999, 87:139-142

2. Prasher VP, Krishnan VH, Clarke DJ, Maliszewska CT, Corbett JA: Deletion of chromosome 2 (p11-p13): case report and review. J Med Genet 1993, 30:604-606.

3. Papagrigorakis MJ, Synodinos PN, Daliouris CP, Metaxotou C: De novo inv (2)(p12q34) associated with Klippel-Feil anomaly and hypodontia. Eur J Pediatr 2003, 162:594-597.

4. Laue K, Janicke M, Plaster N, Sonntag C, Hammerschmidt M: Restriction of retinoic acid activity by Cyp26b1 is required for proper timing and patterning of osteogenesis during zebrafish development. Development 2008, 135:3775-3787.

5. Borsani G, Piovani G, Zoppi N, Bertini V, Bini R, Notarangelo L, Barlati S: Cytogenetic and molecular characterization of a de-novo $t(2 p ; 7 p)$ translocation involving TNS3 and EXOC6B genes in a boy with a complex syndromic phenotype. Eur J Med Genet 2008, 51:292-302.

6. Ross AC, Zolfaghari R: Cytochrome P450s in the regulation of cellular retinoic acid metabolism. Annu Rev Nutr 2011, 31:65-87.

7. Duester $\mathrm{G}$ : Retinoic acid synthesis and signaling during early organogenesis. Cell 2008, 134:921-931.

8. Lee LM, Leung CY, Tang WW, Choi HL, Leung YC, McCaffery PJ, Wang CC, Woolf AS, Shum AS: A paradoxical teratogenic mechanism for retinoic acid. Proc Natl Acad Sci USA 2012, 109:13668-13673.

9. Rothman K, Moore LL, Singer MR, Nguyen US, Mannino S, Milunsky A: Teratogenicity of high vitamin A intake. N Engl J Med 1995, 333:1369-1373.

10. Loureiro KD, Kao KK, Jones KL, Alvarado S, Chavez C, Dick L, Felix R, Johnson D, Chambers CD: Minor malformations characteristic of the retinoic acid embryopathy and other birth outcomes in children of women exposed to topical tretinoin during early pregnancy. Am J Med Genet A 2005, 136:117-121.

11. Sarici D, Akin MA, Kurtoglu S, Uzum K, Kiraz A: Asymmetric Crying Face in a Newborn with Isotretinoin Embryopathy. Pediatr Dermatol 2012, 21:1-2.

12. Wise M, Emmanouil-Nikoloussi EN, Moxham BJ: Histological examination of major craniofacial abnormalities produced in rat foetuses with a variety of retinoids. Eur J Anat 2007, 11:17-26.

13. Maclean G, Dolle P, Petkovich M: Genetic disruption of CYP26B1 severely affects development of neural crest derived head structures, but does not compromise hindbrain patterning. Dev Dyn 2009, 238:732-745.

14. Pennimpede T, Cameron DA, MacLean GA, Li H, Abu-Abed S, Petkovich M: The role of CYP26 enzymes in defining appropriate retinoic acid exposure during embryogenesis. Birth defects research 2010, 88:883-894.

15. Dranse HJ, Sampaio AV, Petkovich M, Underhill TM: Genetic deletion of Cyp26b1 negatively impacts limb skeletogenesis by inhibiting chondrogenesis. J Cell Sci 2011, 124:2723-2734.

16. Laue K, Pogoda HM, Daniel PB, van Haeringen A, Alanay Y, von Ameln S, Rachwalski M, Morgan T, Gray MJ, Breuning MH, et al: Craniosynostosis and multiple skeletal anomalies in humans and zebrafish result from a defect in the localized degradation of retinoic acid. Am J Hum Genet 2011, 89:595-606.

17. Topletz AR, Thatcher JE, Zelter A, Lutz JD, Tay S, Nelson WL, Isoherranen N Comparison of the function and expression of CYP26A1 and CYP26B1, the two retinoic acid hydroxylases. Biochem Pharmacol 2012, 83:149-163.

18. Takeuchi H, Yokota A, Ohoka Y, Iwata M: Cyp26b1 regulates retinoic acid-dependent signals in T cells and its expression is inhibited by transforming growth factor-beta. PLoS One 2011, 6:e16089.

19. White JA, Ramshaw H, Taimi M, Stangle W, Zhang A, Everingham S, Creighton S, Tam SP, Jones G, Petkovich M: Identification of the human cytochrome P450, P450RAl-2, which is predominantly expressed in the adult cerebellum and is responsible for all-trans-retinoic acid metabolism. Proc Natl Acad Sci USA 2000, 97:6403-6408.

20. Wu L, Ross AC: Acidic retinoids synergize with vitamin $A$ to enhance retinol uptake and STRA6, LRAT, and CYP26B1 expression in neonatal lung. J Lipid Res 2010, 51:378-387.

21. Ross AC, Cifelli CJ, Zolfaghari R, Li NQ: Multiple cytochrome P-450 genes are concomitantly regulated by vitamin $A$ under steady-state conditions and by retinoic acid during hepatic first-pass metabolism. Physiol Genomics 2011, 43:57-67.

22. Zolfaghari R, Cifelli CJ, Lieu SO, Chen Q, Li NQ, Ross AC: Lipopolysaccharide opposes the induction of CYP26A1 and CYP26B1 gene expression by retinoic acid in the rat liver in vivo. Am J Physiol 2007, 292:G1029-G1036.

23. Heider MR, Munson M: Exorcising the exocyst complex. Traffic (Copenhagen, Denmark) 2012, 13:898-907.

24. Jafar-Nejad H, Andrews HK, Acar M, Bayat V, Wirtz-Peitz F, Mehta SQ, Knoblich JA, Bellen HJ: Sec15, a component of the exocyst, promotes notch signaling during the asymmetric division of Drosophila sensory organ precursors. Dev Cell 2005, 9:351-363.

25. Mehta SQ, Hiesinger PR, Beronja S, Zhai RG, Schulze KL, Verstreken P, Cao Y, Zhou Y, Tepass U, Crair MC, Bellen HJ: Mutations in Drosophila sec15 reveal a function in neuronal targeting for a subset of exocyst components. Neuron 2005, 46:219-232.

26. Guichard A, McGillivray SM, Cruz-Moreno B, van Sorge NM, Nizet V, Bier E: Anthrax toxins cooperatively inhibit endocytic recycling by the Rab11/ Sec15 exocyst. Nature 2010, 467:854-858.

27. Borggrefe T, Oswald F: The Notch signaling pathway: transcriptional regulation at Notch target genes. Cell Mol Life Sci 2009, 66:1631-1646.

28. Kato Y: The multiple roles of Notch signaling during left-right patterning. Cell Mol Life Sci 2011, 68:2555-2567.

29. Costa RM, Honjo T, Silva AJ: Learning and memory deficits in Notch mutant mice. Curr Biol 2003, 13:1348-1354.

30. Penton AL, Leonard LD, Spinner NB: Notch signaling in human development and disease. Semin Cell Dev Biol 2012, 23:450-457.

31. Fan YS, Jayakar P, Zhu H, Barbouth D, Sacharow S, Morales A, Carver V, Benke P, Mundy P, Elsas LJ: Detection of pathogenic gene copy number variations in patients with mental retardation by genomewide oligonucleotide array comparative genomic hybridization. Hum Mutat 2007, 28:1124-1132

32. Krijgsman O, Israeli D, van Essen HF, Eijk PP, Berens ML, Mellink CH, Nieuwint AW, Weiss MM, Steenbergen RD, Meijer GA, Ylstra B: Detection limits of DNA copy number alterations in heterogeneous cell populations. Cellular oncology (Dordrecht) 2013, 36:27-36.

33. Buffart TE, Israeli D, Tijssen M, Vosse SJ, Mrsic A, Meijer GA, Ylstra B: Across array comparative genomic hybridization: a strategy to reduce reference channel hybridizations. Genes Chromosomes Cancer 2008, 47:994-1004.

34. Schmittgen TD, Livak KJ: Analyzing real-time PCR data by the comparative C(T) method. Nat Protoc 2008, 3:1101-1108.

35. Tay S, Dickmann L, Dixit V, Isoherranen N: A comparison of the roles of peroxisome proliferator-activated receptor and retinoic acid receptor on CYP26 regulation. Mol Pharmacol 2010, 77:218-227.

36. Zimber-Strobl U, Strobl LJ: EBNA2 and Notch signalling in Epstein-Barr virus mediated immortalization of B lymphocytes. Semin Cancer Biol 2001, 11:423-434.

37. White RJ, Schilling TF: How degrading: Cyp26s in hindbrain development. Dev Dyn 2008, 237:2775-2790.

38. Abu-Abed S, MacLean G, Fraulob V, Chambon P, Petkovich M, Dolle P: Differential expression of the retinoic acid-metabolizing enzymes CYP26A1 and CYP26B1 during murine organogenesis. Mech Dev 2002, 110:173-177.

39. Yashiro K, Zhao X, Uehara M, Yamashita K, Nishijima M, Nishino J, Saijoh Y, Sakai $Y$, Hamada H: Regulation of retinoic acid distribution is required for 
proximodistal patterning and outgrowth of the developing mouse limb. Dev Cell 2004, 6:411-422.

40. Shi M, Hu ZL, Zheng MH, Song NN, Huang Y, Zhao G, Han H, Ding YQ: Notch-Rbpj signaling is required for the development of noradrenergic neurons in the mouse locus coeruleus. J Cell Sci 2012, 125:4320-4332.

41. Lim JE, Jin O, Bennett C, Morgan K, Wang F, Trenor CC 3rd, Fleming MD, Andrews NC: A mutation in Sec1511 causes anemia in hemoglobin deficit (hbd) mice. Nat Genet 2005, 37:1270-1273.

42. Meire F, Delpierre I, Brachet C, Roulez F, Van Nechel C, Depasse F, Christophe C, Menten B, De Baere E: Nonsyndromic bilateral and unilateral optic nerve aplasia: first familial occurrence and potential implication of CYP26A1 and CYP26C1 genes. Mol Vis 2011, 17:2072-2079.

43. Oka C, Nakano T, Wakeham A, de la Pompa JL, Mori C, Sakai T, Okazaki S, Kawaichi M, Shiota K, Mak TW, Honjo T: Disruption of the mouse RBP-J kappa gene results in early embryonic death. Development 1995 121:3291-3301.

44. Ishibashi M, Ang SL, Shiota K, Nakanishi S, Kageyama R, Guillemot F: Targeted disruption of mammalian hairy and Enhancer of split homolog-1 (HES-1) leads to up-regulation of neural helix-loop-helix factors, premature neurogenesis, and severe neural tube defects. Genes Dev 1995, 9:3136-3148.

45. Fischer DF, van Dijk R, Sluijs JA, Nair SM, Racchi M, Levelt CN, van Leeuwen FW, Hol EM: Activation of the Notch pathway in Down syndrome: cross-talk of Notch and APP. FASEB J 2005, 19:1451-1458.

46. Hassed SJ, Wiley GB, Wang S, Lee JY, Li S, Xu W, Zhao ZJ, Mulvihill JJ, Robertson J, Warner J, Gaffney PM: RBPJ mutations identified in two families affected by Adams-Oliver syndrome. Am J Hum Genet 2012 91:391-395.

47. Sjogreen L, Kiliaridis S: Facial palsy in individuals with thalidomide embryopathy: frequency and characteristics. J Laryngol Otol 2012, 126:902-906.

48. Reijntjes $\mathrm{S}$, Rodaway $\mathrm{A}$, Maden $\mathrm{M}$ : The retinoic acid metabolising gene, CYP26B1, patterns the cartilaginous cranial neural crest in zebrafish. Int J Dev Biol 2007, 51:351-360.

49. Abu-Abed S, Dolle P, Metzger D, Wood C, MacLean G, Chambon P, Petkovich M: Developing with lethal RA levels: genetic ablation of Rarg can restore the viability of mice lacking Cyp26a1. Development 2003, 130:1449-1459.

50. Niederreither K, Abu-Abed S, Schuhbaur B, Petkovich M, Chambon P, Dolle $P$ : Genetic evidence that oxidative derivatives of retinoic acid are not involved in retinoid signaling during mouse development. Nat Genet 2002, 31:84-88.

51. Ross AC: Retinoid production and catabolism: role of diet in regulating retinol esterification and retinoic Acid oxidation. J Nutr 2003, 133:291S-296S.

52. Echeverri K, Oates AC: Coordination of symmetric cyclic gene expression during somitogenesis by Suppressor of Hairless involves regulation of retinoic acid catabolism. Dev Biol 2007, 301:388-403.

53. Vermot J, Gallego Llamas J, Fraulob V, Niederreither K, Chambon P, Dolle P. Retinoic acid controls the bilateral symmetry of somite formation in the mouse embryo. Science (New York, NY) 2005, 308:563-566.

54. Castella P, Sawai S, Nakao K, Wagner JA, Caudy M: HES-1 repression of differentiation and proliferation in PC12 cells: role for the helix 3-helix 4 domain in transcription repression. Mol Cell Biol 2000, 20:6170-6183.

doi:10.1186/1750-1172-8-100

Cite this article as: Wen et al:: Phenotypic and functional consequences of haploinsufficiency of genes from exocyst and retinoic acid pathway due to a recurrent microdeletion of $2 p 13.2$. Orphanet Journal of Rare Diseases 2013 8:100.

\section{Submit your next manuscript to BioMed Central and take full advantage of:}

- Convenient online submission

- Thorough peer review

- No space constraints or color figure charges

- Immediate publication on acceptance

- Inclusion in PubMed, CAS, Scopus and Google Scholar

- Research which is freely available for redistribution 